This item was submitted to Loughborough's Research Repository by the author.

Items in Figshare are protected by copyright, with all rights reserved, unless otherwise indicated.

\title{
The role of the racket in high-speed tennis serves
}

\section{PLEASE CITE THE PUBLISHED VERSION}

http://dx.doi.org/10.1046/j.1460-2687.2000.00050.x

\section{VERSION}

AM (Accepted Manuscript)

\section{PUBLISHER STATEMENT}

This work is made available according to the conditions of the Creative Commons Attribution-NonCommercialNoDerivatives 4.0 International (CC BY-NC-ND 4.0) licence. Full details of this licence are available at: https://creativecommons.org/licenses/by-nc-nd/4.0/

\section{LICENCE}

CC BY-NC-ND 4.0

\section{REPOSITORY RECORD}

Kotze, Johan, Sean R. Mitchell, and Steve Rothberg. 2019. "The Role of the Racket in High-speed Tennis Serves". figshare. https://hdl.handle.net/2134/18306. 


\title{
The role of the racket in high-speed tennis serves
}

\author{
J. KOTZE, S.R. MITCHELL and S.J. ROTHBERG \\ School of Mechanical and Manufacturing Engineering, \\ Loughborough University, \\ Loughborough, Leicestershire, LE11 3TU, UK
}

Keywords: tennis serve, racket power, coefficient of restitution, grip, sweet spot

\begin{abstract}
The high-speed first serve has become an increasingly dominant factor in tennis, raising concerns over the influence modern racket technology has on the game. One concern is that rackets are now too powerful and so overemphasise a player's ability to produce fast serves. This may help explain the 'penalty shootout' scenario, where match result id dictated by the relative speed and consistency of the players' first serves. There is some concern that on the faster surfaces, maximum service speeds have reached, or are approaching, the service returnee's reaction threshold, making it virtually impossible for players to return the ball. To shed light on the issue the factors relating to 'racket power', the amount a racket magnifies a player's innate ability to impart linear velocity to a tennis ball, need to be considered.
\end{abstract}

Various studies have been performed that shed some light on the subject. This paper presents an overview of the published literature related to 'racket power' in the game of tennis, a review of previous research on specific and sometimes controversial issues. Areas meriting further investigation are identified to encourage future research into racket power.

\section{Introduction}

Over the last 20 years tennis racket designs have changed dramatically. Perhaps most significantly of all, early wooden rackets have given way entirely to rackets constructed from high-tech materials more commonly associated with the aerospace industry. These developments began with a surge in interest in the game in the late 1960s but, ironically, these same advances might ultimately be responsible for the 
demise of tennis prompted by a drastic decline in its merits as a spectator sport. Without detracting from the athleticism and skills of the elite players, modern racket designs appear to enable the serve to be played so reliably at such elevated speeds that even the fastest player reaction times are too slow to permit regular return of service (Groppel, 1986, Arthur, 1992, Brody, 1995). Serve velocities in the professional game were recorded for the first time in 1990, when only 5 players served in excess of 200kph. By 1995 this number had risen to 38 and, although firm data is not yet available, it is widely believed that most of the current top 200 players on the ATP tour are capable of reaching the $200 \mathrm{kph}$ benchmark. Greg Rusedski holds the current world record for the fastest serve recorded in 1998, at 240 kph (Coe, 1999).

The International Tennis Federation (ITF) regards the percentage of sets settled by tiebreaks as a key indicator of the influence of the serve on the game. In the extreme, the service games of some players are seldom broken and this is especially evident on the fast grass courts where the ball skids off the grass, bouncing lower and giving the receiver even less time to react. Data gathered from recent Wimbledon championships show that up to $36 \%$ of sets involving certain players end in tie-breaks, with a very clear correlation between this indicator and service speed (Coe, 1999). Matches on grass courts have been compared to a 'shoot-out', in which the outcome is determined principally by service speed and this is of concern to officials, players and spectators. The Sampras - Ivanesevic Wimbledon final of 1994, in which only 3 of the 206 points lasted more than 4 shots, was described by Fred Perry as “..one of the most boring finals in history”.

Any loss in spectator interest could initiate a downward spiral in which sponsors withdraw support causing a reduction in prize monies and publicity followed by further decline in public interest. This paper reviews the procedures adopted and the data generated by researchers whose vital role in protecting the future of tennis is to provide fundamental understanding of the role of the racket in the high speed tennis serve. (Groppel, 1986, Arthur, 1992, Brody, 1995).

For a long time rules controlling the tennis racket itself were very lenient, allowing the racket to be of almost any material, shape, size or mass. It was only with the introduction of oversize rackets in the 1970's that tennis officials became concerned about racket designs and the ITF (International Tennis Federation) limited the size of the racket head in 1980 (Arthur 1992, Brody 1995). Prior to this the rules stated simply that the ball must be hit with an "implement”, implying the racket could be anything the player wished to hit the ball with (Fisher 1977). Since this intervention, limits on racket specification have become far more stringent in an attempt tot prevent development from drastically 
changing the nature of the game. The current regulations (ITF, 1999) are divided into four sections. In summary, the racket should be characterised by:

1. A flat hitting surface consisting of a uniform pattern of crossed strings. Strings must be free from attached objects.

2. Dimensions not exceeding:

(a) $73.66 \mathrm{~cm}$ for the length and $32.75 \mathrm{~cm}$ in width for the frame and

(b) $39.37 \mathrm{~cm}$ in length and $29.21 \mathrm{~cm}$ in width for the string surface.

3. A frame free of any objects not reducing wear and tear or vibration.

4. A frame free of any device that will allow it to change the physical property of the racket during the playing of a point.

The ITF is currently investigating different ways of monitoring and controlling the importance of the serve. There are various ways to achieve this but this paper is only concerned with the racket's contribution. As a first step towards investigating the influence of the racket in the modern game the paper provides an overview of all the literature related to the factors influencing the racket's role in tennis serves. These issues include; coefficient of restitution; the 'sweet spot'; representative gripping conditions; racket strings and results from motion studies.

\section{Coefficient of restitution}

The coefficient of restitution (COR) is a ratio often used in impact to indicate the capacity to recover from the impact of a given pair of bodies. The COR is a ratio of the restoration impulse magnitude to the deformation impulse magnitude between the two bodies:

$$
C O R=\frac{\int_{t_{0}}^{t} F_{r} d t}{\int_{0}^{t_{0}} F_{d} d t}
$$

where $F_{r}$ and $F_{d}$ are the contact forces during restoration and deformation respectively, $t_{0}$ is the deformation and $t$ the contact time. Under idealised conditions the COR is a constant for the pair of 
bodies and Equation (1) reduces to the ratio of relative velocity after impact to the relative velocity before impact between the two (Meriam and Kraige,1989):

$$
C O R=\frac{v_{r}-v_{b}}{u_{b}-u_{r}}
$$

where $u_{b}$ and $u_{r}$ is the ball and racket velocity before impact, respectively and $v_{b}$ and $v_{r}$ the respective velocities after impact. Equation 2 is the definition most often used to predict velocities resulting from sports ball impacts (Daish, 1972), although the reality that most of these involves materials exhibiting strain rate dependent behaviour introduces some difficulty to its application.

Head (1976) per formed a series of test for his define of the oversized prince racket. To prove the revolutionary improvement of the racket ball were fired at stationary rackets at up to $60 \mathrm{mph}(27 \mathrm{~m} / \mathrm{s})$. In and outbound ball velocities were measured using high-speed motion pictures and COR values calculated. Head defined COR for tennis rackets as the ratio of the struck ball's velocity to the relative incoming velocity. Tests were per formed on under grip clamped, player held and free suspended conditions but only values for the grip clamped conditions were disclosed. The COR measurements were plotted for various points over the string surface and contour maps of areas with COR values within the same range were used to compare different rackets. Values measured varied from 0.3 at the tip of the head to above 0.6 , close to the throat.

In a later paper Brody (1979) compared the maximum COR of different rackets. His results raised the problem of a proper definition for COR testing conditions. Brody's tests were performed with a ball dropped from $3.7 \mathrm{~m}$ onto a racket, head-clamped in a vice. The COR values of approximately 0.85 were considerably higher than the measurements made previously by Head. By clamping the head of the racket, the energy losses to the racket frame are eliminated resulting in higher values for COR. The issue is further complicated by COR values published later for freely suspended, player held and simulated play conditions. To aid clarity these different measures will be indicated by suffix in subsequent sections as follows:

- $\quad \mathrm{COR}_{\mathrm{hc}}=$ head clamped

- $\quad \mathrm{COR}_{\mathrm{gc}}=$ grip clamped

- $\quad \mathrm{COR}_{\mathrm{f}}=$ free suspended
- $\quad \mathrm{COR}_{\mathrm{gp}}=$ grip pivoted

- $\quad \mathrm{COR}_{\mathrm{p}}=$ player held

- $\quad \mathrm{COR}_{\mathrm{s}}=$ simulated play 
Watanabe et al (1979) measured $\mathrm{COR}_{\mathrm{f}}, \mathrm{COR}_{\mathrm{gc}}$ and $\mathrm{COR}_{\mathrm{p}}$ (i.e. under free, grip clamped and player held conditions) for wooden rackets at different impact velocities, ranging between approximately $5 \mathrm{~m} / \mathrm{s}$ and $25 \mathrm{~m} / \mathrm{s}$. The tests revealed that the COR values for these rackets decreased with impact velocities and were independent of grip condition. Values obtained were all in the region of 0.43 , lower than those obtained by Head, but, in calculating COR, Watanabe et al neglect the post impact racket velocity. This is acceptable for the head clamped condition $\left(\mathrm{COR}_{\mathrm{hc}}\right)$ since the racket is prevented from moving, but not for $\mathrm{COR}_{\mathrm{gc}}, \mathrm{COR}_{\mathrm{p}}$ and $\mathrm{COR}_{\mathrm{f}}$ since the post impact racket velocity is significant and would have indicate a difference in true COR (the ratio of pre- and post-impact velocity differences). Hatze later referred to this type of measure as an apparent COR or ACOR (Hatze 1993). Thus, Watanabe et al actually reported values of $\mathrm{ACOR}_{\mathrm{f}}, \mathrm{ACOR}_{\mathrm{p}}$ and $\mathrm{ACOR}_{\mathrm{gc}}$.

In 1980 Elliot performed $\mathrm{ACOR}_{\mathrm{gc}}$ measurements at discrete points along the longitudinal and transverse axes of the strung surface for conventional wooden and oversized rackets at $21 \mathrm{~m} / \mathrm{s}$ (Elliot 1980). These tests revealed a similar map across the racket surface to that found by Head. Along the longitudinal axis the values increase from close to zero at the tip up to a maximum, approximately $2 \mathrm{~cm}$ before the throat, and then decrease slightly towards the throat. Measurements along the transverse axis increased from almost zero at the extremity to a maximum at the longitudinal axis. The $\mathrm{ACOR}_{\mathrm{gc}}$ values measured confirmed Head's claims of a higher $\mathrm{ACOR}_{\mathrm{gc}}$ for oversized rackets compared to conventional rackets. The maximum values for oversized rackets were approximately 0.50 compared to 0.45 for the conventional rackets. This difference is even greater for equivalently displaced off-centre impacts, confirming the increased polar moment theory for oversized rackets initiated by Head (1976).

In 1982 Elliott reported the results of $\mathrm{ACOR}_{\mathrm{s}}$ tests on a range of moving wooden rackets. Head speeds ranged from 6.40-7.42 m/s, depending on racket inertia. The approaching ball velocity was $22.7 \mathrm{~m} / \mathrm{s}$ producing relative incident velocities between the ball and the racket of $29.40-30.12 \mathrm{~m} / \mathrm{s}$. These measurements yielded $\mathrm{ACOR}_{\mathrm{s}}$ values of approximately 0.65 , which is significantly higher than his previously measured $\mathrm{ACOR}_{\mathrm{gc}}$ values. Although Elliott did not address this issue, it raised the question of the importance of static ball in contrast to static racket tests to mimic real playing conditions (Elliott 1982).

Liu addressed the issue of relative velocities by deriving a mathematical model of a static racket and moving ball impact (Liu 1983). Liu defined COR for his static racket/moving ball model using the equation: 


$$
\mathrm{COR}=\frac{v_{s}-v_{b}}{u_{b}}
$$

where $v_{s}$ is the post-impact racket string centre velocity. The measurements of incident and rebound ball velocities, obtained from Watanabe (1979), were substituted into the developed model and produced COR values in the range 0.8 to 0.95 , which correlate well with Liu's model's predictions and measurements by Brody (1981). Liu argues that models for both clamped and free rackets yield almost identical equations relating the so-called Apparent Coefficient of Restitution (ACOR, the ratio between post- and pre-impact ball velocity) and COR and concludes that both are independent of the gripping conditions. This supports Watanabe et al's findings. Both are further substantiated by Baker and Putnam's earlier discovery that the impulses applied to the racket during impact for both free and clamped conditions are identical at impact speeds of 26.5-28.2 m/s (Baker and Putnam, 1979).

In 1991 Casolo derived a method of determining ball velocities from an analysis of the contributions of different limb segments on the racket (Casolo 1991). As part of his model he defines a complicated coefficient of restitution, $\varepsilon$, that keeps account of the energy dissipated during impact. $\varepsilon$ is assumed to be a constant for a specific relative incident velocity and is defined by two equations:

$$
\begin{gathered}
v_{b}-V_{r b}=\sqrt{\varepsilon} V_{r b} \\
v_{r}-V_{r b}=\sqrt{\varepsilon}\left(V_{r b}-u_{b-r}\right)
\end{gathered}
$$

where $u_{b-r}$ is the pre-impact relative speed between the ball and the racket, $V_{r b}$ the ball and racket velocities at the point of maximum ball penetration (velocities are equal at this point). The values of $\varepsilon$ determined, using test data obtained by Van Gheluwe (1985), range from 0.31-38.

Hatze (1992) specifically distinguishes between COR and ACOR and reports COR $_{s}$ values for his human arm simulation rig. During testing, balls were fired at different rackets gripped by a representative gripping device, the 'manusimulator'. The velocities were determined using a high-speed camera and yielded $\mathrm{COR}_{\mathrm{s}}$ values of between $0.758-0.885$ at a ball speed of $20 \mathrm{~m} / \mathrm{s}$.

Hatze (1993) reported further the $\mathrm{COR}_{\mathrm{s}}$ and $\mathrm{ACOR}_{\mathrm{s}}$ results for the manusimulator, as well as the $\mathrm{COR}_{\mathrm{hc}}$ for different rackets. Typical values obtained were; $\mathrm{COR}_{\mathrm{s}}=0.83 ; \mathrm{ACOR}_{\mathrm{s}}=0.43 ; \mathrm{COR}_{\mathrm{hc}}=0.848$. His results also confirm that values for all these COR measures decrease with an increase in incident velocity. 


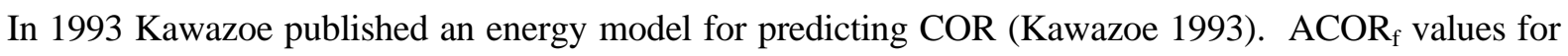
impacts at $30 \mathrm{~m} / \mathrm{s}$ were predicted using the model and then compared with real test data for impacts at $26.4 \mathrm{~m} / \mathrm{s}$. Kawazoe found maximum $\mathrm{ACOR}_{\mathrm{f}}$ values of approximately 0.5 and confirmed the variation of COR along the longitudinal axis of the racket reported earlier by Head (1976) and Elliott.

Wilson (1995) measured the ACOR ${ }_{\mathrm{gc}}$ over the entire surface of rackets at speeds up to $19 \mathrm{~m} / \mathrm{s}$. A map of the entire strung surface is similar to those obtained previously (Head, 1976, Elliott 1980) with maximum values of approximately 0.6 at the throat of the racket. An unexplained result, a second peak located near the tip of the racket, was also reported. It is postulated that this was not detected in other studies because the region was neglected or because the phenomenon does not occur at the higher velocities these studies achieved. However, Grabiner (1983) had performed a similar mapping with an incident velocity of $10.62 \mathrm{~m} / \mathrm{s}$ and did not find this phenomenon either.

Brody (1995) and then later Cross (1997) confirmed and explained Wilson's findings. For impacts at the tip, the ball hits at the 'dead spot', defined by Cross. Initially the ball stops dead at impact while the racket flexes. Before the ball drops, the racket to returns to hit the ball for the second time, approximately $15 \mathrm{~ms}$ later. The net result is a local increase in COR. This phenomenon depends on a match between the racket frequencies and the string ball contact time, which might explain why it is not recorded by all researchers.

In 1997 Brody published a rigid-body model based on energy and momentum conservation equations (Brody 1997). This model incorporates a single $\mathrm{ACOR}_{\mathrm{hc}}$ value measured for the specific racket, and provides an equation for $\mathrm{ACOR}_{\mathrm{f}}$. Using the equation, values were calculated for various locations along the racket's longitudinal axis and compared to experimental results. The calculated values range from 0.267 at the tip to 0.522 at the throat, while the experimental values range from 0.167 at the tip, to a maximum of 0.492 close to the throat, dropping off to 0.485 at the throat. Brody concludes that controlling service speed purely by limiting $\mathrm{ACOR}_{\mathrm{f}}$ is likely to be inadequate, since ball speed varies with $\left(1+\mathrm{ACOR}_{\mathrm{hc}}\right)$ times the racket velocity at impact. However, since the racket velocity achieved is dependent on its inertia properties controlling the net combined effect of ACOR and racket inertia is important.

In the same year, Cross (1997) measured and published the forces, deflections and ACOR $\mathrm{gc}_{\mathrm{gc}}$ values for a ball bouncing on different beams at different locations along their length. Cross found that the beam (or racket) has a well-defined 'dead spot', the point of minimum rebound velocity on a stationary racket, 
near the tip of the racket. However, he agreed with Brody (1997) this spot acts as the point of maximum rebound velocity for a moving racket.

In 1998 Cross further stated that the maximum rebound velocity is near the centre of the strings but shifts towards the racket tip as mass, length and head heaviness increase (Cross 1998).

\section{The 'sweet spot'}

'Sweet spot' is a term commonly used by players and manufacturers. For most players it is a zone on the racket resulting in the most comfortable 'feel' at impact. Consequently it is important they hit the ball in this region as often as possible. To make this more likely manufacturers have tried to design rackets that have the largest possible sweet spot and often refer to this aspect as giving them the definitive advantage over their competitors. Most of the early references to the sweet spot were vague but as recognition of its importance increased it became necessary to find a scientific explanation and definition for the phenomenon. It was soon realised that the term 'spot' was misleading a combination of phenomena occur over a region of the string bed rather than at a definite point.

Considerable attention was given to the sweet spot after the introduction of the Prince over-sized racket in 1976. The racket's inventor, Howard Head, claimed that its wider head had a sweet spot, or power region, almost four times bigger than a conventional racket. He determined the power region by firing a range of balls at a racket and measuring the ACOR at various locations. The sweet spot was defined as the area where the ACOR measured was above a certain value. The Prince racket was the first racket designed to have its centre of percussion (COP) within the playable area of the racket (Head 1976).

In 1979 Brody proposed that the sweet spot be defined as the COP, an explicit point as opposed to a region (Brody 1979). If the ball impacts at this point the racket moves about an instantaneous centre of rotation located in the grip region. The COP is therefore directly linked to a specific grip location and is different for different grip positions. Impact at the COP causes no net reaction force at the hand, at the corresponding grip point. This considerably reduces the shock on the hand and makes the impact feel more pleasant. Since a player's hand contacts the grip at more than a single point, Brody's COP based sweet spot definition might be extended to encompass the string bed region resulting in an instantaneous centre of rotation within the hand contact area. 
Brody later described another possible definition, based on racket vibration work by Hedrick et al (1979) and Lacoste (1976), together with practical ways of determining the differently defined sweet spots (Brody 1981). Impact with the ball causes the racket to oscillate at its natural frequencies. The natural frequencies and corresponding mode shapes are dependent on gripping conditions. For some mode shapes there are points of no oscillation, known as nodes. If struck at these points the ball will generate little response of the racket at the corresponding natural frequency. Hedrick et al measured the string bed node locations, for a number of rackets, where the fundamental mode of a freely suspended racket produced a corresponding second node in the grip region. This raised the question of what is a representative gripping condition for the racket during testing (to be discussed later in more detail).

Much later, Cross defined another point of interest on the strings, the 'dead spot' (Cross 1997). This is the point near the tip of the racket, where the rebound velocity is almost zero when a ball hits a stationary free racket. During play, two phenomena come into effect when a ball hits this 'dead spot'. Most, if not all, modern rackets will vibrate excessively, dissipating a significant amount of the available energy. However, if the racket is rotating about a point near its heel, as is likely, the equivalent mass of the racket at the impact point comes close to that of the ball. As a result, without energy losses, the racket stops dead and all momentum is transferred to the ball. The net effect, including energy losses, is that the COR is locally higher than might otherwise be expected. Although players pay a penalty in terms of increased discomfort and fatigue caused by the increased racket vibration and reaction forces at the hand, the dead spot moves faster than the COP or maximum COR regions because of the rackets angular velocity. This may result in a faster serve.

The concept of the sweet spot has been well summarised by Brody (1987) and Cross (2000). There are four points or regions related to the sweet spot of the racket; the maximum COR area, COP region and the node (Figure 1). Each of these properties effects the way the player perceives impact, i.e. improving or worsening the racket 'feel'. In the next section the influence of the sweet spot on serve velocity will be expanded upon.

\section{Area of maximum COR (maximum energy efficiency).}

This is the area on the racket where the racket returns the most energy to the ball during low racket velocity tests, thus delivering the highest ball speeds. The region is determined by carrying out a series of COR tests across the entire string surface. Most manufacturers use one of two ways to determine this region but the two methods differ considerably leading to confusion. The rackets are either clamped rigidly by the head or at the handle. Clamping at the head reveals a region of high COR close to the 
middle of the racket and with maximum COR values of about 0.85 . Clamping at the handle reveals a region closer to the throat with maximum COR values of about 0.65. The lower COR in the gripclamped condition is a result of the energy being absorbed by the deformation of the racket frame. This energy is not returned to the ball during the contact while, in as with the head clamped condition, no energy is absorbed by the racket frame. For the grip-clamped condition the COR is higher closer to the throat since the frame is effectively stiffer at the throat. The problem with the definition of the high COR region with the clamped handle is that it is too close to the throat of the racket to be utilised by most players. According to research by racket manufacturers, most players hit the ball in the upper 1/3 of the racket face and therefore miss this region. Various attempts by manufacturers are made to shift the power region towards the centre of the head.

\section{Centre of Percussion}

For each point in the COP region there is a conjugate point on the grip where the translation and rotation motion components caused by impact cancel (Figure 2). Hence impact at the COP results in no force on the hand. This point is usually closer to the middle of the racket than the COR.

\section{Node (minimal uncomfortable vibrations)}

Although the exact effects of the gripping conditions are still open to debate, most researchers agree that the racket vibration modes fall somewhere between those for the free suspended and grip-clamped conditions. The clamped condition has a fundamental frequency at about 20-30 Hz, while the second mode and the fundamental mode of the free racket are both in the range 100-150 Hz. The latter frequencies are found to be uncomfortable by players. These modes both have a node close to the centre of the racket face, about $1 / 5$ of the racket length from the tip. An impact at this point will not excite the undesirable frequency and will be more comfortable to the player.

\section{'Dead spot' (Maximum serve velocity)}

The racket velocity at the tip of the racket is the highest for the racket, since it is located furthest from centre of rotation, which located near the grip at the time of impact. Under the high-speed serve conditions, the dead spot, which produce the lowest COR values during the static tests, turns into a momentary 'sweet spot', resulting in the highest rebound ball velocities. 


\section{Representative gripping conditions}

To study experimentally, or even computationally, actual tennis racket performance under ball impact conditions requires careful consideration of the boundary constraints. Perhaps one of the most controversial issues in this respect has been to establish a representative gripping condition. The problem is to find a gripping condition that can be used repeatably in racket tests that faithfully reproduces ‘in play' performance. During real play a human hand grips the racket, and using a human subject arguably produces the most acceptable results. However, the lack of precise control for an individual, the effects of fatigue, the variability between individual players and consequent lack of repeatability are serious obstacles to objective racket testing. Consequently, researchers have resorted to a variety of experimental gripping conditions that can be reproduced in the laboratory with a degree of repeatability, using both simple and complex mechanisms. The issue is further complicated by the fact that under play conditions the racket is subject to arbitrary, high velocity movements. To reproduce the dynamic gripping conditions, let alone realistic relative velocities between racket and ball, is not trivial.

Consequently, there are 5 categories of experimental gripping condition reported in the literature:

1. Hand-held: a racket held by a human hand but not necessarily executing a shot and so not necessarily representative of play.

2. Free: a racket supported by some means that at impact contributes little or no resistance to the racket motion.

3. Grip-pivoted: a racket supported by some kind of pivot at the butt of the handle allowing it to rotate freely about that point during impact.

4. Grip-clamped: a racket clamped at the grip by a restraint that does not allow any rotation or translation in the griped area.

5. Head-clamped: a racket with the head clamped to a solid object, eliminating any contribution from the rest of the racket frame.

Initial investigations of the importance of grip firmness revealed a major influence on rebound velocity (Bunn 1955, Plagenhoef 1970, Broer 1973, Tilmanis 1975). These researchers claimed that a firm grip would prevent the energy lost to racket rotation and therefore return more energy to the ball. 
Hatze (1976) developed a mathematical model of the racket impact by estimating the equations of motion, using the appropriate Lagrangian function. Tests were performed on a wooden racket (strung at $250 \mathrm{~N}$ tension) with ball speeds of up to $34.1 \mathrm{~m} / \mathrm{s}$ under three different conditions, namely; pivoted at the grips; hand-held and real play conditions. Strain gauges were fitted on the racket frame to measure the impulse and at the pivot point on the handle to measure transverse vibrations. Substituting the test values into the model, Hatze predicted an increase in incident velocity causes a decrease in contact time. The model also predicted that an increase in grip firmness would cause an increase in the racket vibration amplitude. The player tests revealed that a loose grip resulted in a $10-15 \%$ decrease in the reaction impulse at the impact point and a reduction in unpleasant vibrations at the hand. Hatze did not record the rebound ball velocity to confirm that there was a net loss to the ball when gripping loosely.

Baker and Putnam (1979) fired balls at rackets (strung at 178 to $267 \mathrm{~N}$ tension) under grip-clamped and free conditions. Part I of the experiment was performed at ball impact speeds of $28.2 \mathrm{~m} / \mathrm{s}$ on different rackets. Pre- and post-impact velocities were recorded using a high-speed camera and used to determine the impulse imparted on the ball. Contrary to earlier findings, no difference in impulse between the free and head-clamped conditions was found for any of the rackets. For part II, the response of a single racket ball impact speed of $26.5 \mathrm{~m} / \mathrm{s}$ was recorded, and the deflections between the two gripping conditions compared. The contact times for both cases were $4 \mathrm{~ms}$ and resultant deflections along the racket were found to be virtually the same during ball contact. After contact the deflections for the different conditions differ dramatically but this occurs after the ball has left the racket. The small deflections during contact can easily be observed to be a result of the two different mode shapes, especially the initial negative deflection of the racket tip. Another interesting observation is that for the grip-clamped condition only $46 \%$ of the total frame deflection, at the impact point, occurs during impact. The small difference in deflection of the handle during impact between the grip-clamped and free condition indicates that gripping forces play some part during impact but the similarities in impact point deflection suggest their effect on the ball is insignificant. Unfortunately, although Baker and Putnam note that the impacts were central to the head, their precise location with respect to the centre of percussion is unknown. Nor did they study the importance of gripping condition to impacts elsewhere along the racket centreline, although they did note that grip conditions affect the outcome of off-centre hits.

Watanabe et al (1979) fired balls at speeds ranging from approximately $5 \mathrm{~m} / \mathrm{s}$ to $25 \mathrm{~m} / \mathrm{s}$ at rackets (strung at $267 \mathrm{~N}$ tension) under three different gripping conditions, namely; grip-clamped; hand-held and a vertically suspended free racket. Incident and rebound velocities were recorded and ACOR values 
calculated. For the entire range of incident velocities, the rebound velocity was found to be independent of the grip conditions with ACOR values for all conditions of approximately 0.43. Watanabe et al did not report the ball impact location with respect to the centre of percussion for their gripping conditions.

In 1979 Brody measured and reported the contact time of a tennis ball on the racket strings as well as the racket oscillation (Brody 1979). The contact time was found to be $4.5 \mathrm{~ms}$ and the half-period of oscillation for different rackets measured at a minimum of $15.3 \mathrm{~ms}$. Brody concluded that most of the energy absorbed by the racket frame is not returned to the ball because the ball has left the strings before the racket has snapped back to release the energy to the ball. The work was concerned with the effect of racket stiffness on rebound velocities but the implication might be that most of the gripping effects are similarly 'lost' to the ball.

In a paper on the tennis racket sweet spot, Brody (1981) dismisses the importance of mode shapes and vibration frequencies for grip-clamped and free rackets. The fundamental frequency of the gripclamped condition was reported to be between $25-40 \mathrm{~Hz}$. The frequency of the second mode was reported to be between $127-168 \mathrm{~Hz}$, similar to the first non-zero mode for the free condition. The node on the racket face for both these conditions is found roughly at the same point, approximately $1 / 5$ of the racket length from the tip. The implication is that, although the racket behaves in some intermediate manner during play, the racket response at the point of impact is quite similar in either the free or gripclamped cases, and so relatively independent of grip condition.

Elliott et al. (1980) published rebound velocity tests comparing over-sized and conventional rackets (strung at $245 \mathrm{~N}$ tension). They claimed the reason for executing their tests on a hand-held racket was because the vibrations from the clamped condition were found to be different in frequency response, amplitude and duration of vibrations, but no data were presented to support this statement.

Brannigan and Adali (1981) developed a mathematical model of a tennis racket including the ball, strings, racket and the hand. The model was used to predict racket behaviour for a free racket. The predicted the first and second natural frequencies for a free racket as approximately $60 \mathrm{~Hz}$ and $100 \mathrm{~Hz}$ respectively, with an impact time of approximately $5 \mathrm{~ms}$, supporting Brody's results for the second mode (Brody 1980, 1997).

In 1982 Elliott projected balls at $22 \mathrm{~m} / \mathrm{s}$ at a moving racket (strung at $245 \mathrm{~N}$ tension), actuated pneumatically and with adjustable grip tightness (Elliott 1982). To control the grip tightness the torque in the bolts of the gripping device was varied between $0.45-0.75 \mathrm{Nm}$. The racket speed $5 \mathrm{~cm}$ from the 
tip of the racket ranged between $6.4-7.4 \mathrm{~m} / \mathrm{s}$ for different rackets. Force transducers located in the racket arm measured reaction force at the grip and stroboscopic photography measured velocities. Impacts along the centre line in longitudinal as well as transverse directions were performed. The largest ACOR was found at the centre of the racket head. At this point a statistically insignificant increase of $7 \%$ in the rebound velocity and of $17 \%$ in reaction impulse was found. However, it was also found that grip tightness had a more pronounced effect on the off-centre impacts. A reduction in ACOR of approximately $15 \%$ was discovered between the racket centre and tip, in line with Hatze's findings.

Contrastingly, Grabiner et al (1983) dropped balls at low speeds (10.62 m/s) onto a “freely-rotating” and a clamped racket (267N tension). Rebound velocities were measured using high-speed cameras. Using a multivariate regression analysis it was found that there was no difference between the rebound velocities from the different clamping conditions, even on off-centre hits. The researchers noted that the ball inbound velocity used is low but fail to note the transverse motion constraint effects for their freelyrotating racket. The racket was suspended horizontally from two wires attached a point on the neck and grip respectively and so resist the effects of a vertical impact.

The mathematical model later developed by Liu (1984) showed that for both the free and grip-clamped conditions, the rebound velocity of the ball was a function of the coefficient of restitution between the ball and the strung racket and independent of the gripping condition.

Missavage et al (1984) developed a similar mathematical model to Liu in 1984 but solved it using a numerical finite difference method. The moment at the handle of the racket was found to be zero during the time of contact, meaning the ball has already left the racket before the impulse has reached the handle. This implies that the gripping condition does not influence the coefficient of restitution. The model predicted that for a drastically stiffened or shortened racket, the grip firmness would affect the coefficient of restitution. An effective increase in stiffness decreases the time for the impulse to reach the handle and produces a positive moment integral i.e. a moment at the hand during impact. Practical tests were performed and found that the COR for a much stiffer racket increased from 0.36 to 0.42 between free and grip-clamped conditions. Similarly for the shortened racket the COR increased from 0.50 to 0.59 . With the increase in effective stiffness for both cases less energy is dissipated into vibrational energy of the racket increasing the energy returned to the ball.

In 1989 Knudson and White mounted two force sensing resistors in the handle of a tennis racket (strung at $245 \mathrm{~N}$ tension) to measure forces in key areas on the hand (Knudson and White 1989). An accelerometer was mounted at the racket's centre of gravity to measure the racket vibration. Players 
were instructed to hit a natural forehand drive at balls fired at them with incident ball velocities of approximately $12 \mathrm{~m} / \mathrm{s}$. The two force sensors measured consistent patterns within $100 \mathrm{~ms}$ of the impact and were found to be out of phase. Comparing the accelerations and force measurements revealed that it took $2 \mathrm{~ms}$ for the impulse to travel from the racket centre of gravity to the handle.

In the same year, Brody fitted a vibration sensor to the throat of the racket to measure the damping time for a racket's natural vibrations (Brody 1989). The vibration found most uncomfortable by players is the first non-zero mode of the free racket, which is between 120 and $200 \mathrm{~Hz}$. The damping time for free rackets was found to be between 180-750 ms, compared to that of a hand-held racket measured as 20-30 ms. It was also found that a tight grip dampens the vibrations within 2 to 3 cycles, much sooner than the loose grip.

Later Hatze (1992) reported the use of this manusimulator, an adaptive test machine to reproduce playertesting conditions for the forehand swing with representative gripping conditions. Balls were fired at $16-26 \mathrm{~m} / \mathrm{s}$, onto a manusimulator-held racket. $\mathrm{COR}_{\mathrm{s}}$ measurements of between 0.758-0.885 were recorded, similar to previous real play test results of $0.750-0.885$, by Groppel et al (1987) and considerably higher than $\mathrm{COR}_{\mathrm{gc}}$ measurements obtained by other researchers, ranging from 0.608-0.699.

In 1992 Leigh and Liu published a model of the ball, strings and frame as a combination of spring and dampers (Leigh and Liu 1992). Results from the model imply that the returned impulse reaches the racket head at 1.7 and 1.2 times of the impact time, after the ball has left the strings, for clamped and free rackets respectively. Interestingly, the results reveal that increased damping in the racket would increase the COR for the racket.

Hatze (1993) also developed and published a theoretical model, based on the energy losses in the ball, strings, racket and grip. COR measurements were obtained from manusimulator-held, grip-clamped and head clamped rackets. Results revealed that at larger impact velocities (22.7-30 m/s) a tighter grip increases the ACOR by approximately 3-8\%. It was determined that there was no difference between static and moving racket tests. Energy losses to the different components were calculated as; strings 2$4 \%$; hand $2 \%$; ball $15 \%$ and frame $58-64 \%$. Approximately $20 \%$ of the original kinetic energy is returned to the ball.

In his paper of 1997, Brody calculated the estimated time it takes for the transverse wave to move towards the handle and back by estimating the wave velocity as $120 \mathrm{~m} / \mathrm{s}$. The propagation time to the handle and back was approximately $8 \mathrm{~ms}$, which supports the theory that the ball leaves the strings 
before the impulse returns. Tests revealed that the frequencies for the possible racket oscillation modes are; grip-clamped from 23-35 Hz; free from 125-200 Hz and hand-held approximately $150 \mathrm{~Hz}$. Brody implies that the free condition best approximates real play results. This is not certain since,as he pointed out earlier, the head node positions and vibration frequencies for the first non-zero mode of the free racket and the second mode of the grip-clamped racket are very similar (Brody 1997).

Cross (1997) supports Brody's dynamic analysis of a racket, by considering the gripping condition's influence in terms of the speed of propagation of the pulse. The speed of the transverse wave through the racket was estimated to be $100 \mathrm{~m} / \mathrm{s}$ and it therefore travels about $50 \mathrm{~cm}$ during a contact time of 5 ms. Since this is shorter than the distance to the handle and back, the ball would have left the strings and gripping has no effect. Cross attached piezoelectric crystals onto a racket to measure vibration characteristics for a static racket under different clamping conditions. Results reveal that the clamped racket does not truly represent the hand-held racket since the fundamental frequency of $23 \mathrm{~Hz}$ measured for the clamped racket was not present. The second mode frequency of the clamped racket shifts from 125 to $100 \mathrm{~Hz}$ for the hand-held racket. This frequency corresponds well with the fundamental frequency of the free racket. In addition to the node at the middle of the strings, the hand-held case exhibits a node near the thumb that again implies a free condition. The head-clamped and free conditions similarly damp the high frequency modes by a factor of 10 and the hand-held condition reduces the fundamental frequency of the free racket from 110 to $100 \mathrm{~Hz}$. Cross concludes that the hand-held racket vibrations are better simulated by the free condition.

In the following year Cross reported vibration tests on rackets by fitting a piezoelectric element and capacitance plates to the racket tip (Cross 1998). The respective frequencies measured for grip-pivoted, hand-held and free conditions were $85 \mathrm{~Hz}, 102 \mathrm{~Hz}$ and $109 \mathrm{~Hz}$. Another series of tests were performed with a hand-held racket fitted with piezoelectric cells fitted from tip to handle. Cross pointed out that the pulse propagation is faster than the analysis of the fundamental mode implies since the impact excites higher vibration modes as well. Using a kinematic model for the upper-arm, forearm and racket chain. He further concludes that the hand plays an important part in racket performance for shots hit not at the centre of percussion.

In summary, the published work can be broadly divided into two categories; publications that claim the gripping conditions do not affect the ball impact, and those that do. However, the division is perhaps not as wide as it initially appears. 
Although there seem to be obvious differences between published results, these can be attributed to different test methods and variables. Some test variables include:

- different rackets, strings and balls

- dimensions and placing of test components like accelerometers and force sensors

- location of the impact point

- impact speed

- $\quad$ string tensions

- $\quad$ the definition of test measures (e.g. COR, ACOR)

Tests were not performed with the same variables for the difference between the impulse results found by Hatze (1976) and Baker and Putnam (1979). Hatze measures impulse using strain gauges on the racket while Baker and Putnam calculated the impulse from the measured ball velocities.

Another cause for differing opinions is the question of 'significance'. For example, Elliott found a $17 \%$ reduction in reaction impulse which, compares well with the $10-15 \%$ found by Hatze. Hatze, however, concluded that the change in impulse will lead to an increase in the "power of the stroke" even though rebound velocity and COR were not measured. On the other hand, Elliott, who measured COR, found changes in reaction impulse have a corresponding "non-significant increase in rebound velocity”.

A popular approach to investigate the gripping condition's influence is to estimate the propagation time of a transverse wave through the racket. The principle is that, for the grip condition to have an effect on the rebound velocity the transverse pulse caused by the impact needs to travel from the point of impact to the handle and back to the impact point. If the ball is still in contact with the strings at this moment the grip will affect the rebound velocity otherwise it will have no effect. Most tests revealed a contact time of 4-5 ms but the complex racket geometry and the short time span makes it difficult to determine the exact propagation time. Values based on the racket's fundamental mode ranged from approximately 8-12 ms but it is not clear that higher frequency vibrations can be neglected.

Many statements were based on vibration analysis of the racket by mathematical models or vibration tests. Again, discrepancies between results were recorded because of differences between variables, especially racket properties and impact point. The vibration frequencies measured for rackets under the different gripping conditions are:

- Grip-clamped: 23 to $35 \mathrm{~Hz}$ (first mode), $125 \mathrm{~Hz}$ (second mode)

- Pivoted: $85 \mathrm{~Hz}$

- Hand-held: 100 to $150 \mathrm{~Hz}$ 
- Free: 125 to $200 \mathrm{~Hz}$

- Strings: $500 \mathrm{~Hz}$ (under all grip conditions)

It is concluded the grip-clamped racket vibration response of the hand-held racket is closer to that of the free racket. For the free condition the mode shapes are essentially the same as for the hand-held condition except for a slight shift in the two nodes towards the end-points of the racket and approximately a $10 \%$ decrease in vibration frequency results. Hence, if tests on vibration aspects of racket impact are performed the free condition will produce the most representative results.

For off-centre impacts there is only one claim, made by Grabiner (1983), to indicate that the gripping has no influence for off-centre impacts, while no other research supports this. The "free-rotating" experimental arrangement Grabiner describes includes an artificial lateral constraint introduced by the two non-compliant suspension cords that perhaps explains his conclusions.

A summary of all the COR results gathered by the various researchers under particular grip conditions is presented in Table 1.

\begin{tabular}{|c|c|c|c|c|}
\hline Year & Researcher & COR type & COR values & $\begin{array}{c}\text { Ball speed } \\
(\mathrm{m} / \mathrm{s})\end{array}$ \\
\hline 1976 & Head & $\mathrm{COR}_{\mathrm{gc}}$ & $0.3-0.6$ & 27 \\
\hline 1979 & Brody & $\mathrm{COR}_{\mathrm{hc}}$ & 0.854 & 8.5 \\
\hline \multirow{3}{*}{1979} & \multirow{3}{*}{ Watanabe et al. } & $\mathrm{COR}_{\mathrm{gc}}$ & 0.44 & 19.30 \\
\hline & & $\mathrm{COR}_{\mathrm{p}}$ & 0.43 & 19.63 \\
\hline & & $\mathrm{COR}_{\mathrm{f}}$ & 0.43 & 16.49 \\
\hline 1980 & Elliott et al. & $\overline{\mathrm{ACOR}_{\mathrm{gc}}}$ & $0.45-0.50$ & 21 \\
\hline 1982 & Elliott. & $\mathrm{ACOR}_{\mathrm{s}}$ & 0.65 & 22.7 \\
\hline \multirow{2}{*}{1984} & \multirow{2}{*}{${ }^{\dagger}$ Missavage et al } & $\mathrm{ACOR}_{\mathrm{f}}$ & 0.36 & 25.3 \\
\hline & & $\mathrm{ACOR}_{\mathrm{gc}}$ & 0.42 & 25.3 \\
\hline 1992 & Hatze & $\mathrm{COR}_{\mathrm{s}}$ & $0.758-0.885$ & 20 \\
\hline \multirow{4}{*}{1993} & \multirow{4}{*}{ Hatze } & $\mathrm{COR}_{\mathrm{s}}$ & 0.83 & 21.19 \\
\hline & & $\mathrm{ACOR}_{\mathrm{s}}$ & 0.43 & 21.19 \\
\hline & & $\mathrm{ACOR}_{\mathrm{s}}$ & 0.42 & 21.16 \\
\hline & & $\mathrm{COR}_{\mathrm{hc}}$ & 0.80 & 21.05 \\
\hline 1993 & Kawazoe & $\mathrm{ACOR}_{\mathrm{f}}$ & 0.5 & 26.4 \\
\hline 1995 & Wilson & $\overline{\mathrm{ACOR}_{\mathrm{gc}}}$ & 0.6 & 19 \\
\hline 1997 & Brody & $\mathrm{ACOR}_{\mathrm{f}}$ & 0.492 & 20 \\
\hline
\end{tabular}

Table 1 : COR results from the literature. 


\section{String effects}

From their own experience and empirical studies, players and coaches have known for some time that lower string tensions enable more powerful shots but that higher tensions promote accuracy. The ball is designed to be imperfectly elastic so increased impact deformation results in increased kinetic energy losses. By contrast, the racket strings are made of more perfectly elastic materials. Reducing the string tension, gauge, pattern density or increasing length reduces the transverse stiffness of the string bed so that the ball deforms less and the strings more during impact. Thus, the strings absorb proportionally more of the impact's energy than the ball. Since the half period of the ball/string bed system is roughly the same as the impact duration, most of the energy absorbed by the strings is then returned to the ball as kinetic energy. Many researchers refer to this phenomenon as the "trampoline” effect (Brody 1987).

There is a lower limit for the maximum COR of a racket when the tension is low that the strings start to move relative to each other, losing energy to friction. Elliott (1982) also found an upper limit for string tension at $245 \mathrm{~N}$, that was later confirmed by Thornhill (1993) who established that the optimum string tension for most strings is between 200N - 245N. Brannigan and Adali (1981) developed a mathematical model of a tennis racquet including the ball, strings, racket and the hand. Results confirmed that a lower string tension results in a longer impact time and a decrease in tension increases the rebound velocity. Thinner and less dense strings also provide more spin, because they "cut" into the ball, giving more grip (Brody 1985).

The increase in shot accuracy with string tension is more difficult to measure. The logical explanation is that the higher tension allows less distortion of the strings so that there is a smaller error angle for offcentre impacts (Brody 1979, 1987). Another reason given is the higher tension leads to more deformation of the ball, which results in a bigger contact interface with the strings and therefore better control (Groppel 1982). Increased stiffness of the racket frame may also have an effect on the accuracy (Widing and Moeinzadeh 1990).

\section{Motion analysis}

Published research includes several studies of human motion during the tennis serve. These provide an understanding of the contribution that different body parts make to achieve a certain racket speed. Figure 4 provide an explanation of medical terms used in the subsequent section. Motion studies also 
provide velocity and acceleration data for important points and segments useful for developing representative testing equipment.

J. Johnson (1957) reported results from a study of speed, slice and accuracy for advanced women players. Using 8-mm film she discovered, rather simply, that speed and accuracy were independent for her test group.

Several years later M.L. Johnson (1976) described the high swing action based on a $128 \mathrm{fps}$ cinematographic analysis performed by Plagenhoef (1971). Three main components of upper body activity were identified:

(i) Cocking: the racket is positioned parallel to and pointing down the spine, with the elbow at approximately $90^{\circ}$ and upper arm pointing forwards and upwards.

(ii) Swing: the racket is swung through approximately $180^{\circ}$. The motion is initiated by shoulder girdle rotation followed by straightening of the flexed arm.

(iii) Pronation: the racket is 'whipped' into the impact by a $180^{\circ}$ rotation of the forearm through the impact.

In 1970 Plagenhoef used footage from a single camera at $64 \mathrm{fps}$ and simple linear momentum theory to explain the service performance of several players (Plagenhoef, 1970). The different grip firmness used by Pilic and Laver changed the effective racket striking mass and, explaining why Pilic could hit a ball at $118 \mathrm{mph}(53 \mathrm{~m} / \mathrm{s})$ with a racket head speed of $73 \mathrm{mph}(34 \mathrm{~m} / \mathrm{s})$ while Laver only achieved $100 \mathrm{mph}$ $(45 \mathrm{~m} / \mathrm{s})$ from $83.5 \mathrm{mph}(37 \mathrm{~m} / \mathrm{s})$.

Adrian (1971) compared the overhead patterns for tennis, volleyball and badminton using two camera systems, at 730 and 775 fps respectively. Angular velocities of body segments calculated over the $6 \mathrm{~ms}$ before impact revealed elbow extension of 1371 degrees/s (23.93 rad/s) and wrist flexion of 2743 degrees/s (47.87 rad/s), with ball speed measured at $39.29 \mathrm{~m} / \mathrm{s}$.

Anderson (1979) published a combined electromyographic and tri-plane cinematographic study (64-100 fps) comparing the ball throw and tennis serve. Although there is some similarity between the two, significant differences between the sequential timing of the two actions suggest players should not train for one by practising the other. A similar study of Japanese male tennis players using $16 \mathrm{~mm}$ film at 100 
to 200 fps was also reported by Miyashita et al (1980) indicating an approximately $300 \mathrm{~ms}$ period negligible muscle contraction, 2 to 500 ms before impact.

In 1983 Elliott and Wood published a 2 camera cinematographic comparison of two different service techniques. Both techniques exhibit a deceleration of racket angular velocity from approximately $0.02 \mathrm{~s}$ prior to impact (Elliott and Wood 1983). That same year Elliott also published a study of topspin generation from the serves of junior and adult players. Using 2 cameras, one for the player (200 fps) the other for the ball (300 fps) he observed topspin values up to $1140 \mathrm{rpm}$ (119 rad/s) for the adults at service speeds of $45 \mathrm{~m} / \mathrm{s}$ (Elliott 1983).

Van Gheluwe and Hebbelinck (1985) recorded the serve action for a top class male and young female using 4 cameras at $400 \mathrm{fps}$. The results provide useful typical serve velocities, especially the racket head velocities (head centre), which were found to be from 30.8 to $32.2 \mathrm{~m} / \mathrm{s}$ before impact and 17.5 to 19.7 $\mathrm{m} / \mathrm{s}$ after impact. The ratio of the racket speed after impact to before impact is calculated as approximately 0.6 and the COR as 0.57 to 0.60 . 50 to $70 \%$ of the racket impact point speed was found to be due to its angular velocity before impact. The more distal the joint the closer its peak velocity was to the time of impact. Van Gheluwe and Hebbelinck concluded that the player applied little impulse to the racket during impact since the net momentum of the racket-ball system remained the same.

Elliott et al (1986) presented a comparison between serve action of four elite male and four elite female players using 3D reconstruction from two 200 fps cameras. The tests showed that males swing the racket with average head speeds of $34.8 \mathrm{~m} / \mathrm{s}$, producing service velocities of $42.4 \mathrm{~m} / \mathrm{s}$. Their data also reveals a decrease in racket angular velocity before impact. Visual interpretation of the film showed that forearm pronation and upper arm endoration has a considerable effect on racket speed approximately 5 ms prior to impact.

In 1987 Van Gheluwe et al reported a 3D study (3 cameras, $300 \mathrm{fps}$ ) of three skilled players. They report an explosive endorotation of the upper arm just after maximum pronation and just before impact and conclude this is an important point of racket speed development (Van Gheluwe et al 1987). However, Van Gheluwe et al (1985) noted earlier that the hand decelerated just before impact and that this helps to generate the racket's angular velocity. It is more likely that instead of generating racket speed, endorotation of the upper arm at this stage merely prevents excessive hand and thus racket grip deceleration. 
In 1988 Elliott published a review of work in this field, postulating that service related injury may be due to high internal forces in the kinematic chain and reduced muscular activity in skilled players (Elliott 1988). In the following year Bahamonde (1989) published joint forces and torques based on an inverse dynamics analysis of 3D cinematographic data. Most torque was generated by the shoulder (internal rotation and horizontal adduction) and elbow (arm extension), with a large torque throughout. The pronation/supination torque was negligible suggesting this is a guiding or releasing action rather than a racket driving one.

In 1988 Buckley and Kerwin published an EMG/cinematographic study of 5 players supporting the findings of other researchers that much of the force creating the high speed elbow extension comes from passive energy flows developed along the body's kinematic chain (Buckley and Kerwin 1988). They noted that the elbow extension velocity of approximately $44 \mathrm{rad} / \mathrm{s}$ is beyond the $20 \mathrm{rad} / \mathrm{s}$ limit imposed by the maximum contractile velocity of human skeletal muscle. In any case, the force that can be generated at such high speed would be minimal. The triceps' contribution, peaking just before impact, is a powerful stabilising co-contraction, rather than a dominant muscle torque.

Several years later, Springings et al (1994) published mathematical equations to determine racket velocity contributions for the kinematic chain segments from a cinematographic analysis of a high quality player with a racket head speed of $27 \mathrm{~m} / \mathrm{s}$. The racket velocity graphs reveal a slight deceleration just before impact but the magnitude of a segment's angular velocity was deemed insufficient to judge its contribution to racket speed. For example, the lower horizontal cross-flexion speed of the upper arm is $1 / 3$ that of forearm pronation but 'contributes' 6.5 as opposed to $4 \mathrm{~m} / \mathrm{s}$ to the head speed. They do not, however, show conclusively whether segment velocity is the cause of head speed or whether segment velocity is simply required not to impede head speed.

In Cohen et al (1994), correlated anthropometric data and serve velocity amongst 40 tournament players using a Sony Video 8 Handycam, a Jugs radar gun and upper extremity strength and usability measuring equipment. They concluded that serve velocity depends on flexibility of dominant wrist and shoulder flexion, dominant shoulder internal rotation at $0^{\circ}$ of abduction, and torque generation during elbow extension.

Recently, Elliott et al (1995) presented a cinematographic (3 cameras, $200 \mathrm{fps}$ ) comparison between the service actions of 11 elite players. Internal rotation of the upper arm reached its peak $5 \mathrm{~ms}$ before impact. Segment contributions to the $31 \mathrm{~m} / \mathrm{s}$ horizontal racket head speed were calculated as:

- $\quad$ internal rotation of upper arm (54.2\%) 
- $\quad$ hand flexion (31.0\%)

- $\quad$ horizontal flexion \& abduction of upper arm (12.9\%)

- $\quad$ linear shoulder velocity (9.7\%)

- $\quad$ forearm pronation (5.2\%)

- $\quad$ forearm extension (-14.4\%)

To summarise, there appears to be lack of agreement over the source of speed in the service action, perhaps because the position measurement errors are so large in most cases causing the inverse dynamics calculations to be inconclusive as well as difficult. Buckley and Kerwin's paper perhaps provides the key to understanding the combined results of so many researchers. The force/contraction speed limitations for human skeletal muscle suggest the service energy is generated early in the action by contraction of the larger muscles at low speed. This is transferred in a 'whiplash' action through the kinematic chain with consequent sequential angular velocity magnification. Distal segment rotation and muscular activity during this period serve only to guide, release and unimpede the energy transfer.

Since all researchers agree that peak racket velocity occurs slightly before impact it appears service impact simulation can be adequately achieved in the laboratory under constant velocity conditions.

\section{Conclusions}

It is evident that the designs of rackets have changed considerably in the past 20 years and there is no doubt this has had a dramatic effect on the speed of the modern game. No credit should be taken away from the players who handle these powerful instruments with incredible speed and precision react to balls projected at tremendous speeds. Unfortunately, as in any other modern sport, the game's survival lies in its popularity with the public of whom most are just spectators. The real full effects of the latest rackets are still concealed because most of the top players prefer playing with the rackets they are used to, instead of the most powerful ones. These players are skilled enough to sacrifice the extra power for more control. Stefan Edberg was quoted on the introduction of the new more powerful wide-bodied rackets as saying: "Wide-bodies are just too powerful. Balls just take off. That's fine if you're hitting the ball flat, but once you try to put on topspin, you can't get a grip on the ball." The real problem will start when the next generation of players, who grow up using these powerful rackets, get to the top rankings. The words of Goran Ivanisevic, once one of the fastest servers, echo this concern: "You can see kids age 12 and 13 playing with wide-bodied rackets hitting the ball harder than me." (Arthur, 1992) 
It was observed that the highest incident ball velocities at which tests were performed was at approximately $30 \mathrm{~m} / \mathrm{s}$. These velocities are considerably lower than the serve velocities reached by the top players. It is necessary, therefore, for a series of COR tests to be performed in the 40 to $60 \mathrm{~m} / \mathrm{s}$ range. These tests will evaluate the validity of the tests performed at lower speeds.

Another shortcoming observed in the literature, is the availability of more accurate 3-dimensional, motion data from under normal play conditions. Most of the motion data was acquired analysing footage captured either with single cameras, or at relatively low frame rates. This induces significant deviations in results, leaving certain phenomena during the high-speed serve unexplained. 


\section{References}

1. Adrian, M.J. and Enberg, M.L., Sequential Timing of Three Overhead Patterns. Kinesiology Review, 1971: p. 1-9.

2. Anderson, M.B., Comparison of Muscle Patterning in the Overarm Throw and Tennis Serve. Research Quarterly, 1979. 50(4): p. 541-553.

3. Arthur, C., Anyone for slower tennis. New Scientist, 1992, 2 May: p. 24-28.

4. Bahamonde, R.E, Kinetic analysis of the serving arm during the performance of the tennis serve. Journal of Biomechanics, 1989. 22(10): p. 983.

5. Baker, J.A. and Putnam, C.A., Tennis Racquet and Ball Responses During Impact Under Clamped and Free-standing Conditions. Research Quarterly, 1979. 50(2): p. 164-170.

6. Brannigan, M. and Adali, S, Mathematical modelling and simulation of a tennis racquet. Medicine and Science in Sports and Exercise, 1981. 1: p. 44-53.

7. Brody, H., Physics of the tennis racquet. American Journal of Physics, 1979. 47(6): p. 482-487.

8. Brody, H., Physics of the tennis racquet II: The "sweet spot". American Journal of Physics, 1981. 49(9): p. 816-819.

9. Brody, H., Tennis science for tennis players. 1987, Pennsylvania: University of Pennsylvania Press.

10. Brody, H., Vibration Damping of Tennis Racquets. International Journal of Sport Biomechanics, 1989. 5: p. 451-456.

11. Brody, H., How Would a Physicist Design a Tennis Racket. Physics Today, 1995. March: p 26-31.

12. Brody, H., A modest proposal to Improve Tennis. TennisPro, 1996, January - February: p. 8-9.

13. Brody, H., The physics of tennis III. The ball-racket interaction. American Journal of Physics, 1997. 65(10): p. 981-987.

14. Broer, M., The efficiency of human movement. 1973: Philadelphia: W.B. Saunders.

15. Buckley, J.P. and D.G. Kerwin, The role of the biceps and triceps brachii during tennis serving. Ergonomics, 1988. 31(11): p. 1621-1629.

16. Bunn, J.W., Scientific principles of coaching. 1955: New York: Prentice-Hall.

17. Casolo, F. and G. Ruggieri, Dynamic analysis of the ball-racket impact in the game of tennis. Meccanica, 1991. 26: p. 67-73.

18. Coe, A., The balance Between Technology and Tradition in Tennis, 1999, Discussion paper for ITF Board of Directors, ITF: London. p. 1-42. 
19. Cross, R.C., The dead spot of a tennis racket. American Journal of Physics, 1997. 65(8): p. 754-764.

20. Cross, R.C., Optimising the Performance of a Tennis Racket. ITF technical report, 1998: p. 1-25.

21. Cross, R.C., Effects of string tension on racquet performance. Sports Engineering, 2000. In press.

22. Cohen, D.B., et al., Upper Extremity Physical Factors Affecting Tennis Serve Velocity. American Journal of Sports Medicine, 1994. 22(6): p. 746-750.

23. Daish, C.B., The Physics of Ball Games. 1972: The English Universities Press Ltd. 180.

24. Elliott, B.C., Blanksby B.A., and. Ellis R, Vibration and rebound velocity characteristics of conventional and oversized tennis racquets. Research Quarterly for Exercise and Sport, 1980. 51(4): p. 608-615.

25. Elliott, B.C., Tennis: The Influence of Grip Tightness on Reaction Impulse and Rebound Velocity. Medicine and Science in Sports and Exercise, 1982. 14(5): p. 348-352.

26. Elliott, B.C., The influence of tennis racquet flexibility and string tension on rebound velocity following a dynamic impact. Research Quarterly for Exercise and Sport, 1982. 53(4): p. 277-281.

27. Elliott, B., Spin and the Power Serve in Tennis. J. of Human and Movement studies, 1983. 9: p. 97104.

28. Elliott, M.B., 3-Dimensional Cinematographic Analysis of the tennis serve. International Journal of Sport Biomechanics, 1986. 2(4): p. 260-271.

29. Elliott, B.C., Biomechanics of the serve in Tennis: A Biomedical Perspective. Sports Medicine, 1988. 6: p. 285-294.Elliott, M.N., Contributions of Upper Limb Segment Rotations During the Power Serve in Tennis. J. of Applied Biomechanics, 1995. 11: p. 433-442.

30. Fisher, A., Super Racket - is this the Shape of Things to Come in Tennis. Popular Science, 1977: p. $44,46,150$.

31. Grabiner, M., Groppel J., and Campbell K., Resultant tennis ball velocity as a function of off-centre impact and grip firmness. Medicine and Science in Sports and Exercise, 1983. 15(6): p. 542-544.

32. Groppel, J., Gut reactions. World Tennis, 1982. 31(6): p. 42.

33. Groppel, J.L., The Biomechanics of Tennis: An Overview. International Journal of Sports Biomechanics, 1986. 2: p. 141-155.

34. Groppel, J.L., et al., The effects of string type and tension on impact in midsized and oversized tennis racquets. International Journal of Sports Biomechanics, 1987. 3: p. 40-46.

35. Hatze, H., Forces and duration of impact, and grip tightness during the tennis stroke. Medicine and Science in Sports, 1976. 8(2): p. 88-95.

36. Hatze, H., The Effectiveness of Grip Bands in Reducing Racquet Vibration Transfer and Slipping. Medicine and Science in Sports and Exercise, 1992. 24(20): p. 226-230. 
37. Hatze, H., Objective Biomechanical Determination of Tennis Racquet Properties. International Journal of Sport Biomechanics, 1992. 8: p. 175-287.

38. Head, H., Tennis Racket, U.S. Patent 3999756, 28 December 1976.

39. Hedrick, K., Ramnath, R. and Mikic, B., An authoritative new method of evaluating rackets. World Tennis. 1979. 27(4). p. 78-81.

40. Hatze, H., The Relationship Between the Coefficient of Restitution and Energy Losses in Tennis Racquets. Journal of Applied Biomechanics, 1993. 9: p. 124-142.

41. ITF. ITF Rules of Tennis 1999. in Annual General Meeting of ITF. 1998. United Kingdom: Wilton, Wright \& Son Limited.

42. Johnson, J., Tennis Serve of Advanced Women Players. Research Quarterly, 1957. 28(2): p. 123131.

43. Johnson, M.L., High Velocity Serve. Athletic Journal, 1976. 56: p. 44-46.

44. Kawazoe, Y., Coefficient of Restitution between a Ball and a Tennis Racket. Theoretical \& Applied Mechanics, 1993. 42: p. 197-208.

45. Lacoste, F.R., Tennis Rackets and similar implements with vibration damper, U.S. Patent 3941380, 2 March 1976.

46. Leigh, C.L. and Lu, W., Dynamics of the Interactions Between Ball, Strings, and Racquet in Tennis. International Journal of Sport Biomechanics, 1992. 8: p. 181-206.

47. Liu, Y., Mechanical analysis of racquet and ball during impact. Medicine and Science in Sports and Exercise, 1983. 15(5): p. 388-392.

48. Meriam, J.L. and Kraige, L.G., Engineering Mechanics: Dynamics. Fourth ed. 1998: John Wiley \& Sons, Inc. 725.

49. Missavage, R., Baker J., and Putnam C., Theoretical modelling of grip firmness during ball-racquet impact. Research Quarterly for Exercise and Sport, 1984. 55(3): p. 254-260.

50. Miyashita, T.S., Muscular activities in the tennis serve and overhand throwing. Scand. J. Sports Science, 1980. 2(2): p. 52-58.

51. Plagenhoef, S., Fundamentals of Tennis. 1970, Englewood Cliffs, New Jersey: Prentice-Hall.

52. Plagenhoef, S., Patterns of Human Motion: A Cinematographical Analysis. 1971, Englewood Cliffs, New Jersey: Prentice-Hall.

53. Springings, E., et al, A three-dimensional kinematic method for determining the effectiveness of arm segment rotations in producing racquet-heas speed. Journall of Biomechanics, 1994. 27(3): p. 245254. 
54. Thornhill, P.M., Baker J.S., and. Cooper S.M, Interaction between tennis string type and tension and the subsequent effect upon ball rebound velocity. Journal of Human Movement Studies, 1993. 24: p. 157-167.

55. Tilmanis, G.A., Advanced tennis. 1975: Philedelphia: Lea and Febiger.

56. Van Gheluwe, B. and Hebbelinck M., The Kinematics of the Service Movement in Tennis: A ThreeDimensional Cinematographical Approach, In D.A. Winter, R.W. Norman, R.P. Wells, K.C. Hayes and A.E. Patla (Eds), Biomechanics IX-B, 1985, Champaign, IL: Human Kinetics: p. 521-526.

57. Van Gheluwe, B., De Ruysscher I. and Craenhals J., Pronation and Endoration of the Racket Arm in a Tennis Serve. 1987.

58. Watanabe, T.I.Y. and Miyashita M., Tennis: The Effects of Grip Firmness on Ball Velocity after Impact. Medicine and Science in Sports and Exercise, 1979. 11(4): p. 359-361.

59. Widing, M. and Moeinzadeh M., Finite modelling of a tennis racquet with variable string patterns and tensions. International Journal of Sport Biomechanics, 1990. 6(1): p. 78-91.

60. Wilson, J.F. and Davis J.S., Tennis Racket Shock Mitigation Experiments. Journal of Biomechanical Engineering, 1995. 117: p. 479-484. 


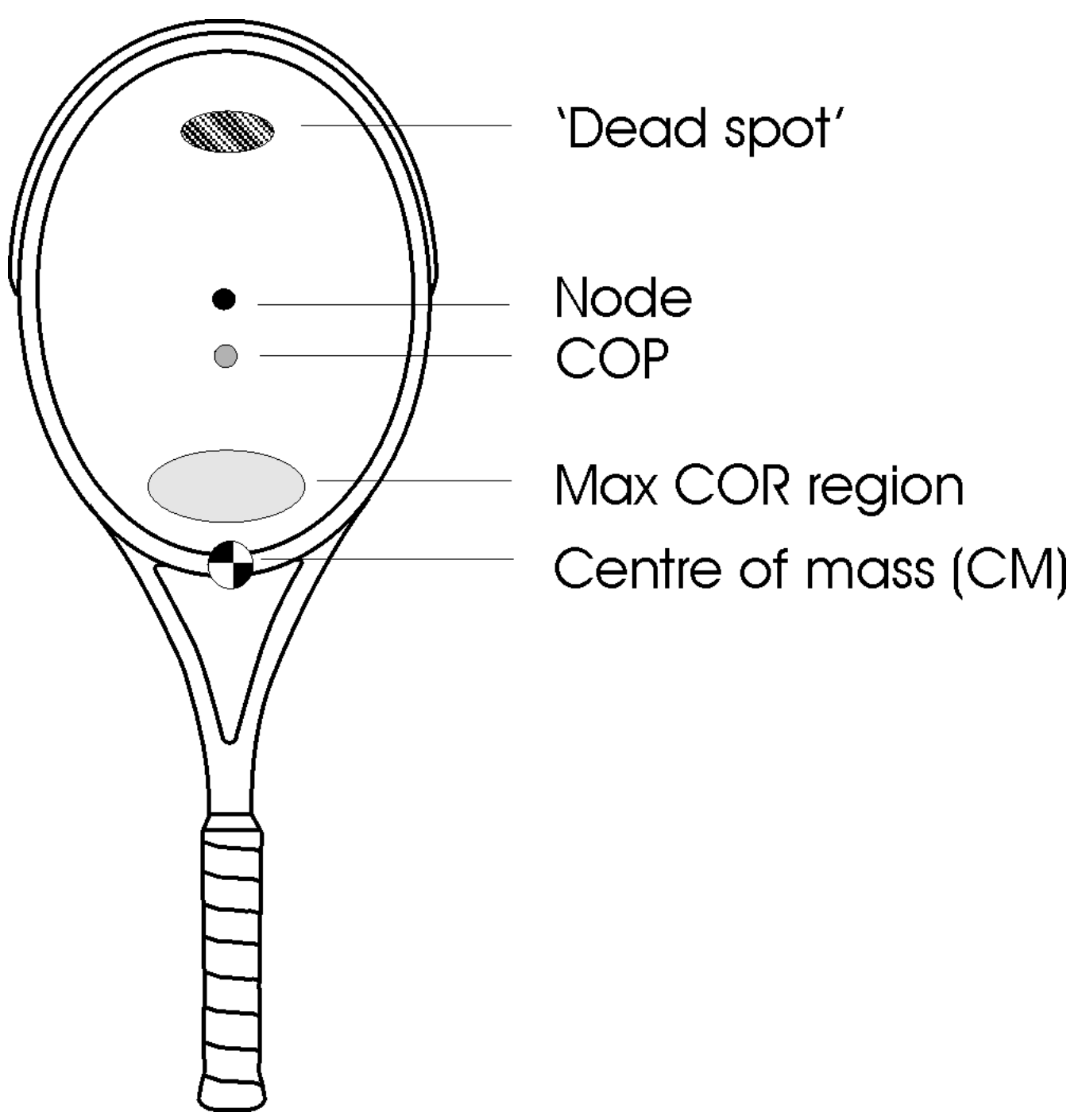

Figure 1: Common locations of four definitions of the 'sweet spot' of a racket. 


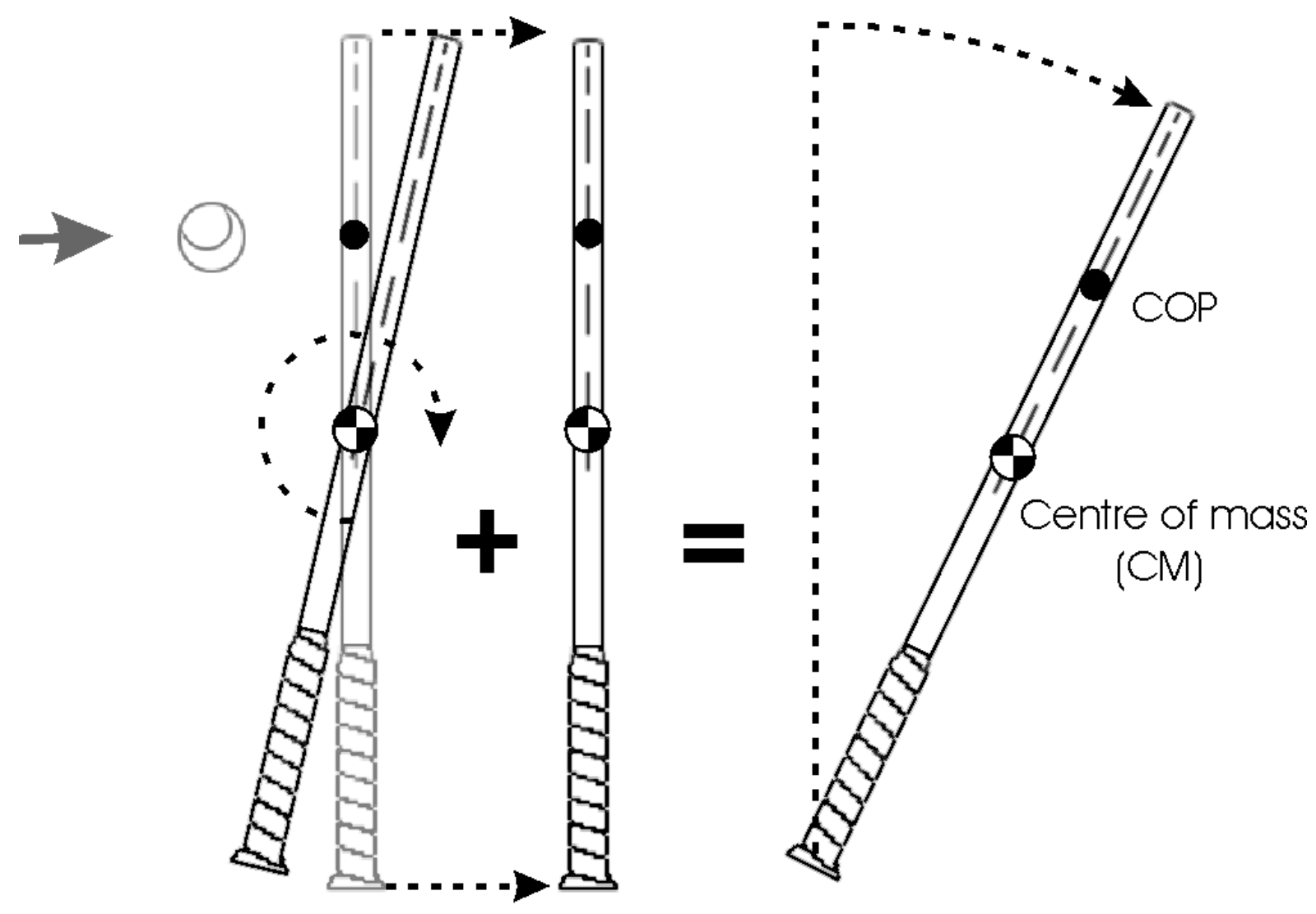

\section{Rotation + Translation $=$ Rotation about about $\mathrm{CM}+$ grip point}

Figure 2: Centre of percussion. 
Mode 1

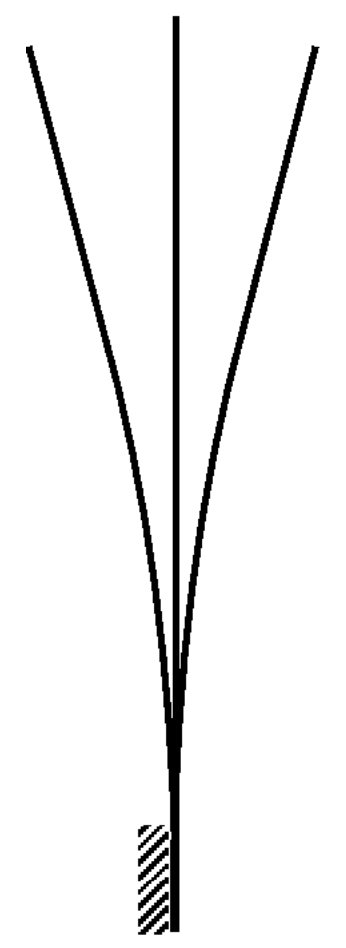

CLAMPED
Mode 2

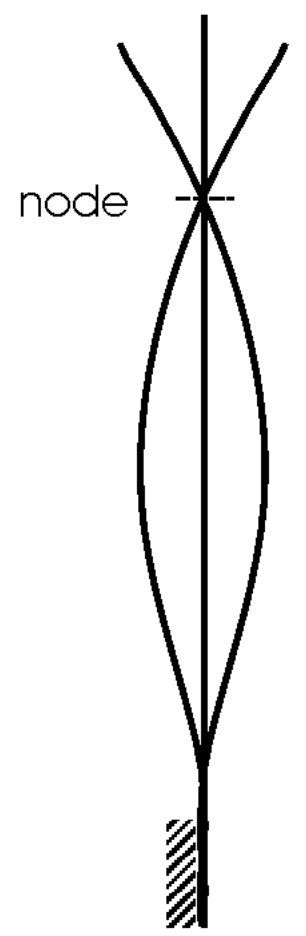

FREE-STANDING

Figure 3: Mode shapes for clamped and free-standing racket. 


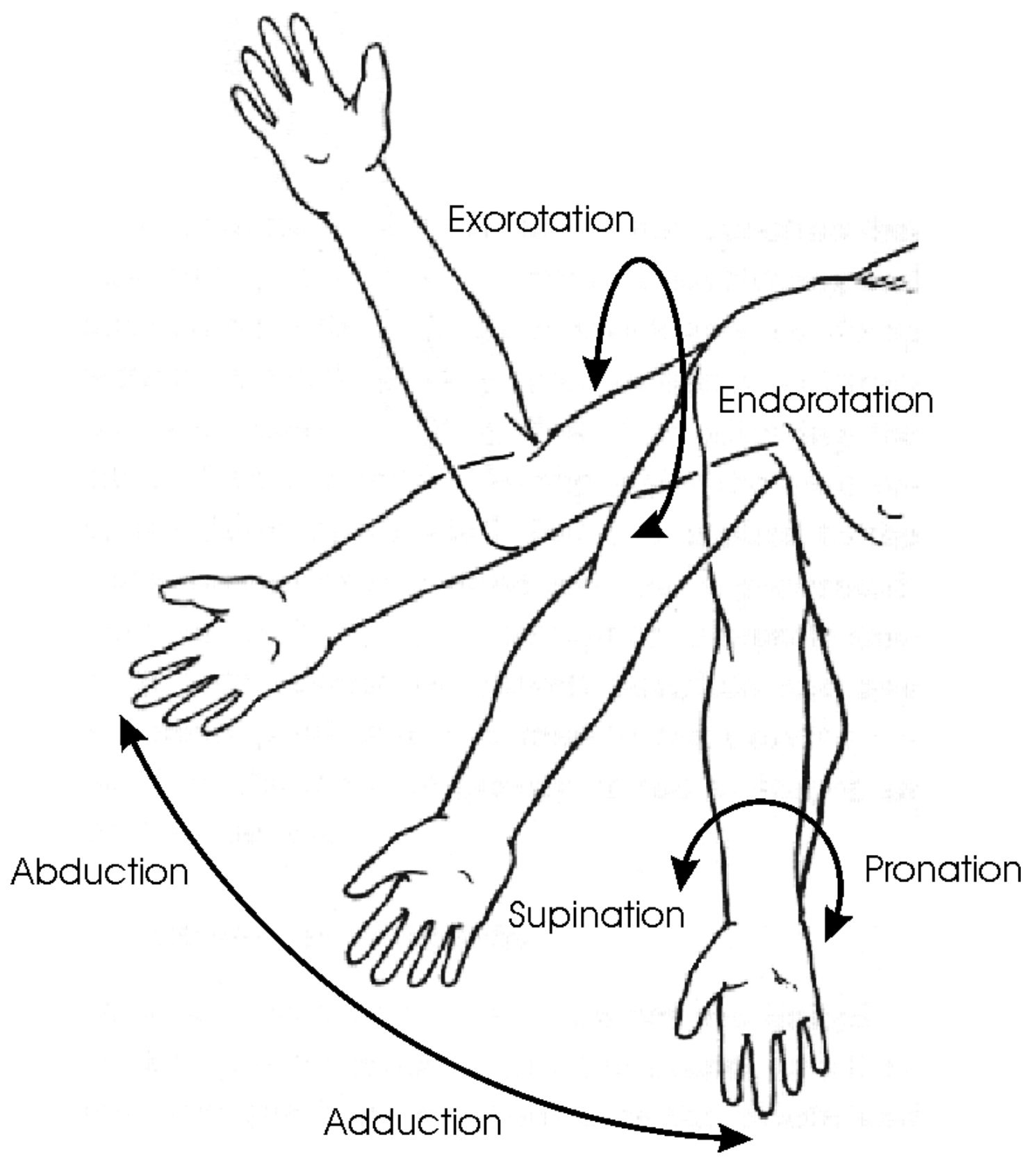

Figure 4: Range of motions of the upper limb. 